\title{
Bacterial meningitis in a known case of steroid-resistant nephrotic syndrome
}

\author{
Saili Vishwanath Bunde ${ }^{1}$, Mumtaz Sharif ${ }^{2}$, Amit Saxena ${ }^{3}$ \\ From ${ }^{1}$ Junior Resident, ${ }^{2}$ Professor and Head of Unit, ${ }^{3}$ Associate Professor, Department of Pediatrics, Dr. D. Y. Patil University, Navi Mumbai, \\ Maharashtra, India
}

\begin{abstract}
Nephrotic syndrome (NS) is a kidney disorder in which, excess protein is being excreted through urine. While most cases of idiopathic nephrotic syndrome respond to steroid therapy and experience a limited number of relapses prior to complete remission, some cases suffer from frequent relapses and become steroid-dependent or are primarily steroid-resistant. Treatment options are limited to immunosuppressive drugs with significant side effect profiles. Infections in nephrotic syndrome are common and can be severe. Meningitis is one of the complications associated with nephrotic syndrome. Here, we report a child with steroid-resistant nephrotic syndrome (SRNS) with meningitis. Early detection and appropriate treatment of these complications can be lifesaving.
\end{abstract}

Key words: Seizures, Streptococcal pneumonia, Cyclophosphamide, Steroid

$\mathrm{N}$ ephrotic syndrome (NS) is a glomerular disorder typically characterized by gross proteinuria, hypoalbuminemia, hyperlipidemia, and peripheral edema. Diagnosis is generally based on clinical features and investigations such as blood tests, renal imaging, and biopsy [1]. Complications of nephrotic syndrome can be either disease-associated or drug related. Disease-associated common complications include infections, thromboembolism, hypovolemic crisis, cardiovascular problems, and acute kidney injury (AKI) [2]. Bacterial meningitis is a severe and life-threatening infection that may lead to death, especially when treatment initiation is overdue. It is mainly due to various risk factors including reduced immunoglobulin concentration via urinary loss of $\mathrm{IgG}$, depletion of properdin factor B, the deleterious effects of edematous tissue resembling culture medium, decreased bactericidal activity of leukocytes by immunosuppressive therapy, and inefficient perfusion of the spleen due to hypovolemia [3-6].

\section{CASE PRESENTATION}

An 8-year-old female child was brought to our casualty with complaints of convulsions aborted by self at home and by medication in the casualty, followed by post-ictal drowsiness and bowel and bladder incontinence. There was no history of aura or fever, neither any history suggestive of cranial nerve involvement.

The patient was a known case of steroid-resistant nephrotic syndrome diagnosed as minimal change disease in April 2020.

\section{Access this article online}

Received - 28 May 2021

Initial Review - 16 June 2021

Accepted - 18 August 2021

DOI: $10.32677 / \mathrm{IJCH} .2021 . v 08.109 .3039$
Initially, the child was on tablet prednisolone at $60 \mathrm{mg} / \mathrm{m}^{2}$ and in August 2020, she was started on injection of cyclophosphamide as she was diagnosed as steroid-resistant nephrotic syndrome. Due to non-compliance and improper follow-up, the child developed relapse and parents started oral steroids on their own. There was no significant family history. Birth history and developmental history were normal. Child was immunized till 5 years of age as per the National Immunization schedule. No optional vaccines were given. On examination, the child was unconscious, Glasgow Coma Scale (GCS) was 8/15 (E2 V2 M4) with tachycardia and hypertension. Generalized edema was present. Patient was maintaining saturation on room air. Weight, height, and BMI of the child were normal. Multiple striae were present on the arm, shoulder, abdomen, and thigh. Moon facies was present. Rest head-to-toe examination was normal. The abdomen was distended with smiling umbilicus. There was no tenderness or organomegaly. Fluid thrill was present. Upon examination of the Central Nervous System (CNS), the child had altered sensorium, deep tendon reflexes were brisk and signs of meningeal irritation (neck Stiffness, Kernig's, and Brudzinski's signs) were present. Rest CNS examination was normal. Investigations (Table 1) were sent which showed increased total leukocyte count (TLC), raised C-reactive protein (CRP), hypokalemia, hypoalbuminemia, and raised albumin: creatinine ratio. Urine routine showed proteinuria. There was no evidence of hematuria. Examination of the cerebrospinal fluid (CSF) revealed 20 cells $/ \mathrm{mm}^{3}, 20 \%$ polymorphs, $8.3 \mathrm{mg} / \mathrm{dL}$ protein and $108 \mathrm{mg} / \mathrm{dL}$ sugar. CSF culture showed growth of Streptococcus pneumoniae.

Correspondence to: Saili Vishwanath Bunde, 801, Shree Sai Deep Apt, Near Bhagirathi Bungalow, Bhusar Ali, Kalwa, Thane-400605, Maharashtra, India. Phone Number: (+91)9967767555. E-mail: sailibunde28@gmail.com

(C) 2021 Creative Commons Attribution-NonCommercial 4.0 International License (CC BY-NC-ND 4.0). 
Table 1: Clinical investigation performed serially for the patient

\begin{tabular}{lcccc}
\hline \multicolumn{5}{c}{ Serial investigation } \\
\hline Total leukocyte count (TLC) & 21.9 & 7.8 & 16.3 & 7.6 \\
C-reactive protein (CRP) & 19.5 & 12.6 & & 4.9 \\
Erythrocyte sedimentation rate (ESR) & 70 & & & \\
Serum Potassium & 2.9 & 3.7 & 4.1 & 4.4 \\
Serum Albumin & 1.7 & 1.9 & & 2.4 \\
\hline
\end{tabular}

Magnetic resonance imaging (MRI) was suggestive of post-ictal encephalitis. After establishing the diagnosis, supportive treatment including injection of ceftriaxone, amikacin, fosphenytoin, and levetiracetam, intravenous (IV) fluids, and antihypertensive were started. There were no signs of raised inflammation of connective tissue (ICT). Proteinuria and edema were gradually resolved. Patient was stabilized and injection of cyclophosphamide and oral prednisolone was started at $60 \mathrm{mg} / \mathrm{m}^{2} /$ day. The child responded with the given treatment. A final diagnosis of steroid-resistant nephrotic syndrome (SRNS) with meningitis was made. Repeat imaging of the brain showed resolution of brain parenchymal involvement. Patient has been asked to follow-up for further cyclophosphamide therapy.

\section{DISCUSSION}

The hallmark of nephrotic syndrome is massive proteinuria, leading to decreased circulating albumin levels which was seen in our patient. Edema occurs due to decrease in plasma oncotic pressure, as a consequence of low serum albumin levels, causing extravasation of fluid into the interstitial space.

Patients with nephrotic syndrome, particularly children, are at increased risk of developing serious bacterial infections, including pneumonia, empyema, and peritonitis [7]. Sepsis, meningitis, and cellulitis are other serious infections that can occur in children with nephrotic syndrome [8]. The increased risk for infection is related to renal losses of IgG. Loss of opsonizing factors may specifically increase the susceptibility to encapsulated bacterial infection, in particular to pneumococcal infections that are potentially lethal $[9,10]$. The predominant bacterial causes are Streptococcus pneumoniae and Gramnegative enteric organisms such as Escherichia coli. [4]. Patients with NS are frequently in an immunosuppressive state because of urinary loss of immunoglobulins and the use of immunosuppressive drugs. Therefore, they are at a higher risk of suffering from infections followed by high morbidity and mortality. These infections are also the main reasons for hospitalization along with delayed response to steroid or discontinuation of steroid therapy in some cases. Our patient suffered from bacterial meningitis which was secondary to immunosuppressant. Early diagnosis and initiation of treatment are essential to prevent morbidity and mortality.

\section{CONCLUSION}

It can be concluded that meningitis and is a rare complication of NS, and an early detection and management of the same can be life saving.

\section{REFERENCES}

1. Adam Z, Krejcí M, Pour L, Stepánková S, Cermáková Z, Voska L, et al. Complete remission of nephrotic syndrome and improvement of renal function in a patient with light chain deposition disease following high dose chemotherapy with transplantation of autologous haematopoietic stem cells. A case study and review of literature. Vnitr Lek 2009;55:1089-96.

2. Park SJ, Shin JI. Complications of nephrotic syndrome. Korean J Pediatr 2011;54:322-8

3. Krishnan C, Rajesh TV, Shashidhara HJ, Jayakrishnan MP, Geeta MG. Major infections in children with nephrotic syndrome. Int J Contemp Pediatr 2017;4:346-50.

4. Wu HM, Tang JL, Cao L, Sha ZH, Li Y. Interventions for preventing infection in nephrotic syndrome. Cochrane Database Syst Rev 2012;2012:CD003964.

5. Chopra D, Kini P, Bhaskaranand N, Aroor S. Spectrum of infections in children with nephrotic syndrome. Int J Infect Dis 2010;14:e419.

6. Nourbakhsh N, Mak RH. Steroid-resistant nephrotic syndrome: Past and current perspectives. Pediatric Health Med Ther 2017;8:29-37.

7. lwadhi RK, Mathew JL, Rath B. Clinical profile of children with nephrotic syndrome not on glucorticoid therapy, but presenting with infection. J Paediatr Child Health 2004;40:28-32.

8. Lebel A, Kropach N, Ashkenazi-Hoffnung L, Huber-Yaron A, Davidovits M. Infections in children with nephrotic syndrome: Twenty years of experience. Clin Pediatr (Phila) 2020;59:692-8.

9. Rheault M. Nephrotic syndrome: Updates and approaches to treatment. Curr Treat Options Pediatr 2016;2:94-103.

10. Candelier JJ, Lorenzo HK. Idiopathic nephrotic syndrome and serum permeability factors: A molecular jigsaw puzzle. Cell Tissue Res 2020;379:231-43.

Funding: None; Conflicts of Interest: None Stated.

How to cite this article: Bunde SV, Sharif M, Saxena A. Bacterial meningitis in a known case of steroid-resistant nephrotic syndrome. Indian J Child Health. 2021; 8(9):338-339. 